\title{
AS PRÁTICAS RESTAURATIVAS COMO MEIO EFICAZ DE SOLUÇÃO DOS CONFLITOS ESCOLARES ENVOLVENDO O BULLYING
}

\author{
SANTOS, M.F1; COSTA,M.M.M².
}

PALAVRAS CHAVE: Bullying. Práticas Restaurativas. Escolas.

\section{RESUMO}

0 presente artigo, a partir da Lei ${ }^{\circ}$ 13.185/2015 que Institui o Programa de Combate à Intimidação Sistemática (Bullying) e visa não punir o agressor, mas encontrar meios alternativos de responsabilizá-lo por seus atos, questiona se há possibilidade de aplicar as Práticas Restaurativas como meio de prevenir e mediar o bullying dentro das escolas. Objetivou-se na pesquisa analisar a possibilidade de aplicar as Práticas Restaurativas enquanto política pública de conscientização, prevenção e enfrentamento a condutas que sejam intimidadoras aos alunos, com a participação ativa de professores e de toda a comunidade acadêmica nesse processo; realizar uma breve análise sobre o conceito de bullying enquanto fenômeno em constante transformação, essencialmente na era da globalização e estudar a Lei $n^{\circ} 13.185 / 2015$ a partir de suas nuances e perspectivas jurídicas e sociais. Empregou-se como método de abordagem o dedutivo, uma vez que, para chegar-se a uma conclusão sobre o que foi proposto, fez-se uso de dados encontrados sobre cidades na Região Sudeste e Sul do país em que projetos de Justiça Restaurativa vêm sendo implantados nas escolas. Como técnicas de pesquisa se utilizou a bibliográfica e a documental. Constatou-se que as Práticas Restaurativas estão sendo aplicadas e mostrando resultados positivos em escolas do Brasil, visto que, primam não pela punição, mas pela reconstrução das relações.

\section{RESTORATIVE PRACTICES AS AN EFFECTIVE MEANS OF SOLUTION OF SCHOOL CONFLICTS INVOLVING BULLYING}

KEYWORDS: Bullying. Restorative Practices. Schools.

\section{ABSTRACT}

The present article questions from the Law $n^{\circ} 13.185$ / 2015 that institutes the Program to Combat Systematic Bullying and aims not to punish the aggressor, but to find alternative means to hold him accountable, if there is a possibility of applying the Practices Restorative as a means of preventing and mediating bullying within schools. The objective of the research was to analyze the possibility of applying Restorative Practices as a public policy of awareness, prevention and coping with behaviors that are intimidating to students, with the active participation of teachers and the entire academic community in this process; to carry out a brief analysis on the concept of bullying as a phenomenon in constant transformation, essentially in the era of globalization and to study Law $n^{\circ}$ 13.185 / 2015 from its nuances and juridical and social perspectives. Deductive method was used as a method of arriving at a conclusion about what was proposed, using data found on cities in the Southeast and South of the country in which Restorative Justice projects come being implanted in schools. As bibliographic and documentary research techniques were used as research techniques. It was found that the Restorative Practices are being applied and have shown positive results in schools in Brazil, since they are not punishment but reconstruction of relations.

\footnotetext{
${ }^{1}$ Acadêmica do curso de Direito da Universidade de Santa Cruz do Sul. E-mail: mylenafrancysantos@gmail.com.

2 Professora do Departamento de Direito da Universidade de Santa Cruz do Sul. E-mail: marlim@unisc.br.
} 


\section{INTRODUÇÃO}

O bullying tem se tornado, cada vez mais, um fato preocupante entre os jovens e muito destacado nos meios de comunicação. Praticado na maior parte das vezes no ambiente escolar, esse fenômeno tem causado diversos problemas de convivência e acarretado consequências muito prejudiciais ao desenvolvimento de crianças e adolescentes. Perante a proporção que tomou esse tipo de violência, viu-se a necessidade da elaboração de uma lei para tentar prevenir e eliminar a prática do bullying dentro das escolas. Deste modo, foi promulgada em 2015, a Lei $n^{\circ}$. 13.185, que Institui o Programa de Combate à Intimidação Sistemática (Bullying). Essa lei evidencia a necessidade de prevenir e combater a prática do bullying, capacitar docentes para enfrentar o problema e orientar pais e responsáveis para detectar a violência e evitar, sempre que possível, punir o agressor procurando meios alternativos que promovam a responsabilização e a mudança do comportamento do mesmo. Diante dessa lei questiona-se, há possibilidade de aplicar as práticas restaurativas como meio de prevenir e mediar o bullying dentro das escolas?

A Justiça Restaurativa com suas Práticas Restaurativas começou a funcionar a cerca de dez anos no Brasil e se tornou válida para resolver conflitos por tratar do mesmo com sensibilidade e primando pela escuta das partes envolvidas, proporcionando-lhes poder de decisão. Desta forma, vê-se nesse modelo de justiça uma alternativa muito interessante para tratar a violência dentro das escolas, em especial o bullying, visto que, não objetiva punir o agressor, mas sim reconstruir as relações que foram prejudicadas.

0 presente artigo parte da premissa de que a violência pode emergir em todos os ambientes em que 0 conflito não é negociado e onde haja intolerância ao diferente. Assim sendo, tanto a escola pública quanto a particular são possíveis geradoras de violência, apesar de apresentarem realidades distintas, principalmente no que se refere à estrutura material da escola e à classe social de sua demanda. Nessa perspectiva, analisar-se-á com base na Lei de Bullying n 13.185/2015 (Programa de Combate à Intimidação Sistemática), a viabilidade da implementação das Práticas Restaurativas nas escolas enquanto política pública de conscientização, prevenção e enfrentamento a condutas que sejam intimidadoras aos alunos, com a participação ativa de professores e de toda a comunidade acadêmica nesse processo. Ademais, será feita uma breve análise sobre o conceito de bullying enquanto fenômeno em constante transformação, essencialmente na era da globalização e se abordará a Lei $n^{\circ} 13.185 / 2015$ a partir de suas nuances e perspectivas jurídicas e sociais no Brasil. Para a construção deste artigo utilizar-se-á como método de abordagem o dedutivo, uma vez que se objetiva analisar dados de cidades na Região Sudeste e Sul do país em que projetos de Justiça Restaurativa nas escolas vêm sendo implantados, para então, chegar-se a uma conclusão substancial sobre o que foi proposto. Como técnicas de pesquisa serão utilizadas a bibliográfica e a documental com a finalidade de sistematizar o referencial teórico para encontrar possíveis respostas ao problema apresentado, com consulta à produção científica relevante acerca do tema.

\section{O BULLYING ENQUANTO FENÔMENO PREOCUPANTE DENTRO DAS ESCOLAS}

Os casos de violência dentro das escolas são comuns no dia a dia dos alunos, porém um se destaca entre os demais: a violência sistemática, mais conhecida como bullying. Este fenômeno é muito frequente entre os jovens e muitas vezes se prolonga no tempo. As vítimas, na maioria das vezes, se calam a respeito das agressões sofridas e cabe a quem está próximo detectar o problema e tentar intervir. "Tais atitudes têm se 
desdobrado em conflitos muito agressivos a ponto de quebrar as regras de limites, diálogo e tolerância. Atitudes de violência, às vezes explícitas, agressões verbais, corporais e assassinatos dentro e fora da escola" (PEREIRA; RODRIGUES, 2012, p.24).

A expressão bullying, deriva da palavra bully, de origem inglesa, que significa "valentão, não possuindo tradução para o português.

A expressão bullying corresponde a um conjunto de atitudes de violência física e/ou psicológica, de caráter intencional repetitivo, praticado por bully (agressor) contra uma ou mais vítimas que se encontram impossibilitadas de se defender. Seja por uma questão circunstancial ou por uma desigualdade subjetiva de poder, por trás dessas ações sempre há um bully que domina a maioria dos alunos de uma turma e "proíbe" qualquer atitude solidária em relação ao agredido (SILVA, 2010, p.21).

A violência provocada pelo bullying acontece de diversas formas e é praticada, na maioria das vezes, contra os jovens que se mostram mais frágeis e quietos (introspectivos). Segundo Antunes (2010), não ser autoconfiante, ter alguma deficiência, não ter a pele branca, apresentar necessidades educacionais especiais, ter uma orientação sexual diferente, não possuir amigos da mesma condição social, constitui um grupo suscetível de sofrer bullying porque são iguais no aspecto de fugirem de um padrão de normalidade exigido dentro de determinado grupo social.

Os agressores são quase sempre os "populares" da escola, que se consideram superiores aos demais e que se acham no direito de importunar. Por vezes, esses jovens passam por situações de violência e desrespeito dentro de suas próprias casas e isso reflete em seu relacionamento com os colegas, por acreditarem ser um comportamento normal ou pela sensação de superioridade que essas atitudes Ihes proporcionam. Felizardo (2017), descreve características do ponto de vista subjetivo de quem pratica a intimidação sistemática e segundo ele, o agressor de bullying geralmente espera que todos façam suas vontades e que suas ordens sejam sempre cumpridas. Gosta de sensação de poder, tem dificuldade de se relacionar, sofre intimidações, é maltratado em sua casa, é humilhado pelos adultos, vive sob pressão psicológica e sente-se inseguro e inadequado ao meio em que está inserido.

De acordo com Silva (2010), existem formas diretas e indiretas de ser praticada a violência sistemática (bullying), mas dificilmente a vítima sofre apenas um tipo de agressão, o que acarreta não apenas no distanciamento da vítima de sua vida social, mas também, muitas vezes, na evasão escolar. 0 bullying pode ser manifestado de forma física, verbal, virtual, psicológica, moral e até mesmo sexual.

A violência causada pelo bullying pode resultar em consequências preocupantes no decorrer da vida de quem a sofre, sendo ela física ou verbal. Como ocorre na fase inicial da vida, que compreende a infância e adolescência, a intimidação sistemática acarreta vários problemas na construção da identidade das vítimas, que geralmente se tornam adultos inseguros, com baixa autoestima e com problemas de relacionamento, por carregarem consigo um estigma de inferioridade imposto pelos demais. Nesse sentido, Pereira e Rodrigues (2012) reforçam que é preciso ter consciência de que essas atitudes fazem mal ao ser humano, pois a longo prazo essas pessoas agredidas podem não conseguir se relacionar com outras pessoas do seu meio, já que ao serem vítimas, geralmente separam-se do grupo e vivem isolados para não sofrerem mais agressões.

É de extrema importância que os casos envolvendo o bullying sejam observados pelos professores já no início, quando as primeiras intimidações ocorrem, para que não se alastrem e tomem uma grande proporção causando sérios danos. Segundo Silva (2010), hoje a escola não pode ser vista apenas como o local onde é absorvido o conteúdo programático, mas sim um espaço onde as relações interpessoais são de grande importância para o desenvolvimento dos jovens, contribuindo no seu preparo para a vida adulta. 
Desta forma, é importante que todas as relações sejam trabalhadas dentro do ambiente escolar, tanto para serem fortalecidas, quando se trabalha com valores como a amizade, o respeito, o amor; quanto para serem resolvidas, primando pela reconstrução das conexões rompidas quando se trata de situações conflituosas, que envolvem discussões e violência. Esse diálogo quanto as relações interpessoais dentro da escola se tornam fundamentais para combater o bullying, visto que, na grande maioria das vezes, as vítimas se calam diante da agressão por sentirem medo e até mesmo vergonha, o que dificulta que os casos sejam percebidos e tratados.

Os pais e responsáveis também têm papel importante frente a essas situações e devem reservar atenção especial às atitudes de seu filho, tanto no âmbito familiar, quanto no rendimento escolar do mesmo (CAVALHEIRO; PORTO, 2017). Partindo desse pensamento, também é papel dos pais intervir quando notarem comportamentos estranhos em seus filhos, para que juntamente com a escola possam encontrar uma solução para o problema. Porém, infelizmente, grande parte dos pais deixa essa incumbência somente à escola, transferindo suas responsabilidades pela educação de seus filhos somente aos docentes. Segundo Minayo (2000), são frequentes as queixas dos professores no sentido de que muitos pais não cooperam com a escola, alegam falta de tempo para dedicarem-se suficientemente aos filhos e que a entrada da mulher no mercado de trabalho seria outro agravante do problema. Desse modo, as crianças ficam em uma situação de vulnerabilidade e acabam se calando ao invés de procurar ajuda.

Existem vários fatores que podem influenciar os jovens para que se tornem agressivos e tenham comportamentos desrespeitosos com seus colegas e demais crianças e adolescentes que façam parte do seu convívio, chegando-se assim, a prática do bullying. Nesse sentido, Antunes (2010), relata que há pesquisas sobre bullying onde são mencionadas teorias sobre as possíveis causas da agressividade repetitiva e sem motivos aparentes entre colegas, porém as respostas dadas pelas mesmas teorias não possuem aprofundamento. Tais causas vão de fatores relacionados com os próprios indivíduos, trazendo a agressividade ou a aprendizagem de comportamentos agressivos como algo inerente ao ser humano; até seu impacto com a sociedade desigual, relacionamento com a família, escola e absorção dos conteúdos dos programas de televisão.

Atualmente existe uma preocupação significativa por parte das escolas sobre como enfrentar a intimidação sistemática, inclusive muitos educadores desenvolvem projetos com o intuito de combater o bullying. 0 Poder Legislativo, visando conter esse fenômeno, elaborou a Lei $n^{\circ} 13.185$ que Institui o Programa de Combate à Intimidação Sistemática (Bullying). Sancionada em 2015 e entrando em vigor em 2016, essa lei busca auxiliar as escolas no processo de prevenção e diminuição do problema. De acordo com o artigo $4^{\circ}$ temse, entre outros objetivos:

II. Capacitar docentes e equipes pedagógicas para a implementação das ações de discussão, prevenção, orientação e solução do problema.

III. Implementar e disseminar campanhas de educação, conscientização e informação.

VIII- evitar, tanto quanto possível, a punição dos agressores, privilegiando mecanismos e instrumentos alternativos que promovam a efetiva responsabilização e a mudança de comportamento hostil; (BRASIL, 2015).

Além do bullying cometido de forma presencial, outra forma desta violência ser praticada vem se expandindo nos dias atuais. Com o avanço da tecnologia trazendo consigo o acesso à internet, a intimidação sistemática passou a ser praticada também no ambiente virtual. As mídias sociais passaram a ser usadas pelos agressores para a prática do bullying por proporcionarem a estes o anonimato. Deste modo, os ofensores se sentem confortáveis ao desferir a violência por não precisarem entrar em contato direto com a vítima e por esta não saber de quem está recebendo as agressões. Para o ofensor, o fato de não estar frente a frente com a vítima 
diminui as chances de um possível arrependimento, já que não presencia o mal que está causando e isso lhe torna propenso a dizer coisas que não diria pessoalmente, se tornando mais atrativo praticar o bullying (JAHNKE; GAGLIETT, 2012).

Mesmo não sendo praticado de forma física, devido o meio de que se utiliza, estas agressões são tão prejudiciais quanto as sofridas presencialmente por afetarem o sistema psicológico da vítima que não sabe como deter as ofensas nem por quem elas são proferidas. 0 bullying praticado no ambiente virtual é denominado cyberbullying e causa sérios constrangimentos:

[...] mensagens instantâneas são disparadas, via internet ou celular, em que o autor se faz passar por outro, adotando nicknames semelhantes, para dizer coisas desagradáveis ou para disseminar intrigas e fofocas. [...] Fotografias são tiradas, com ou sem o consentimento das vítimas, sendo alteradas por intermédio de montagens constrangedoras, incluindo ofensas, piadinhas, comentários sexistas ou racistas (JAHNKE; GAGLIETT, 2012, p.4).

0 cyberbullying também está previsto na Lei $n^{\circ} 13.815 / 2015$ que Institui o Programa de Combate à Intimidação Sistemática (Bullying):

Parágrafo único. Há intimidação sistemática na rede mundial de computadores (cyberbullying), quando se usarem os instrumentos que lhe são próprios para depreciar, incitar a violência, adulterar fotos e dados pessoais com o intuito de criar meios de constrangimento psicossocial (BRASIL, 2015).

Visto dessa forma, o cyberbullying também necessita ser discutido e prevenido dentro das escolas, uma vez que causa consequências tão preocupantes quanto o bullying "tradicional". Como já mencionada, a prevenção é uma aliada indispensável na busca de combate a este problema, para que os casos de intimidação sistemática não venham a ocorrer. Uma forma de se colocar em prática a prevenção é através de diálogos e projetos que promovam a integração entre alunos, para que entendam a magnitude que suas atitudes podem alcançar e, desta forma, seja possível diminuir e até mesmo eliminar o bullying, independente do modo como é praticado.

Ainda pensando em conter os casos de bullying, em 29 de abril de 2016 foi sancionada a Lei $n^{\circ} .13 .277$ que institui o dia 7 de abril como Dia Nacional de Combate ao Bullying e à Violência na Escola (BRASIL, 2016). Essa data foi escolhida por conta da tragédia ocorrida em 2011, quando um rapaz de 24 anos adentrou a Escola Municipal Tasso de Oliveira, no bairro de Realengo, no Rio de Janeiro, e matou 11 crianças (MEC, 2018). Relatos de quem conhecia o jovem atestam que ele teria sofrido bullying enquanto estudou na mesma escola, assim, esse caso trágico exemplifica o que estudiosos dizem sobre as consequências psicológicas que a intimidação sistemática pode causar em suas vítimas.

Uma alternativa muito válida nos dias de hoje para trabalhar a violência no ambiente escolar, incluindo o bullying, é a Justiça Restaurativa, com suas Práticas Restaurativas, que promovem meios de serem sanados os conflitos e reconstruídas as relações prejudicadas. Por conta disso, abordar-se-á no próximo capítulo a Justiça Restaurativa através de suas Práticas Restaurativas como meio de resolver a violência nas escolas.

\section{A JUSTIÇA RESTAURATIVA ATRAVÉS DE SUAS PRÁTICAS RESTAURATIVAS COMO MEIO DE SE REESTABELECER OS ELOS DE CONVIVÊNCIA DENTRO DAS ESCOLAS}

A Justiça Restaurativa surgiu a partir de movimentos sociais que objetivavam encontrar outros métodos de resolver conflitos que fossem diferentes do atual sistema jurídico que não possibilita que as partes envolvidas na situação conflituosa sejam ouvidas e nem possibilita que se reparem os danos sofridos (PORTO, 2008). Por meio 
das suas Práticas Restaurativas, a Justiça Restaurativa então surge para que os conflitos possam ser tratados dentro da própria comunidade onde ocorreram e se chegue a um consenso para que o elo entre as pessoas seja restabelecido.

O modelo de Justiça Restaurativa já atua a dez anos no Brasil e sua prática tem se alastrado pelo território brasileiro. É reconhecida como uma forma de solução de conflitos que trabalha de forma sensível e criativa com as vítimas e ofensores primando pela escuta dos mesmos e com a aproximação entre vítima e agressor juntamente com suas respectivas famílias e a sociedade em que estão inseridos (FARIELLO, 2015).

Justiça Restaurativa é uma abordagem que envolve todos aqueles que têm interesse em determinada ofensa; reunidos em círculo, criam espaço protegido para a autoexpressão e, utilizando processos inclusivos e cooperativos, identificam e tratam danos e necessidades, bem como obrigações deles decorrentes. Envolve, na medida do possível, todos os que sofrem o impacto para restaurar os laços de relacionamento e confiabilidade social rompidos pelo conflito. È um convite ao diálogo respeitoso (FELIZARDO, 2017, p.88).

Com o modelo de Justiça Restaurativa há possibilidade das partes envolvidas no conflito disporem do mesmo poder de decisão, não colocando esse importante fato ocorrido em suas vidas sob responsabilidade de outra pessoa, ou seja, do juiz. Nesta forma de resolver questões conflituosas há um intermediador que apenas se destina a conduzir as partes a um acordo amigável. Deste modo, as Práticas Restaurativas oferecem maior participação dos interessados, inclusive no controle integral do processo na busca pela pacificação dos conflitos, do que na justiça tradicional, já que quase todos os métodos são desenvolvidos fora do poder Judiciário, podendo inclusive, ocorrer dentro da própria comunidade (COSTA; DIEHL, 2015).

É necessário que se esclareça um ponto importante. Justiça Restaurativa e Práticas Restaurativas não são a mesma coisa, visto que, as práticas antecedem a Justiça Restaurativa; Práticas Restaurativas são as reuniões familiares, os círculos restaurativos, reuniões restaurativas, círculos de construção de paz. Já a Justiça Restaurativa abrange uma vasta quantidade de práticas e programas que trazem consigo uma forma humanizada de tratar o conflito, o crime, a violência, procurando atender também a necessidade das vítimas. Há opiniões diferentes sobre o que de fato é a Justiça Restaurativa, algumas acreditam ser um processo de encontro, uma metodologia de trabalhar com o crime e a injustiça envolvendo os interessados na decisão; outras dizem ser uma mudança do entendimento do que é justiça que visa, ao ignorar o dano ocasionado pelo crime, reparar ao contrário de impor uma pena; há também quem entenda que significa um conjunto de valores voltados à cooperação e à resolução da situação conflituosa, uma forma de concepção reparativa (DIEHL; PORTO, 2016).

A sociedade está habituada com o modelo de justiça que se vale apenas do Direito Penal, da imposição de penas e da formalidade para resolver conflitos, mas onde não há a assistência a vítima. Na justiça tradicional, os fatores que levaram o conflito a se consumar não são avaliados com a mesma importância do ato gerado pelo mesmo, por isso, a resposta que se recebe no processo é voltada apenas para cessar o conflito e não visa superálo tratando suas origens (COSTA; DIEHL, 2017). Ainda nas palavras de Felizardo (2017, p.9):

Nossos paradigmas de justiça têm origem na justiça retributiva, e a justiça restaurativa aparece para transformar a visão de justiça. Segundo a justiça retributiva, o crime é uma violação contra o Estado, definida pela desobediência à lei e pela culpa. A justiça determina a culpa e inflige dor numa disputa entre ofensor e Estado, regida por regras sistemáticas.

Entretanto, os processos em sua grande maioria podem ser resolvidos pelas partes envolvidas, sem ser necessário recorrer à justiça tradicional e suas formalidades e punições. Essa desjudicialização, além de 
contribuir para que não se sobrecarregue o sistema judiciário, traz mais conforto às vítimas, pois, no sistema tradicional ao qual estamos acostumados a recorrer como explica Zehr (2008), em vez de devolver o poder a vítima e lhe deixar participar do processo de justiça, reforça-se o dano já causado, negando às vítimas essa possibilidade. Ainda segundo o mesmo autor, a justiça é também uma experiência e deve ser vivenciada como algo concreto; as vítimas, em sua grande maioria, não se contentam em apenas ouvir que as devidas providências estão sendo tomadas; elas querem ser também consultadas e ter participação no processo.

Diante deste quadro angustiante para a vítima que se destacam os benefícios de trabalhar com a Justiça Restaurativa, composta por suas práticas e programas. Nos dias atuais, as Práticas Restaurativas estão sendo implantadas nas escolas como meio de evitar e enfrentar a violência, incluindo o bullying, através da prevenção e reconsolidação das relações, promovendo um melhor relacionamento entre escola, família e comunidade. Desta forma, as Práticas Restaurativas “Destinam-se à restauração e à reparação das relações através do diálogo, dos círculos de paz e das reuniões restaurativas, procurando reconectar e recuperar relações" (COSTA; DIEHL 2017).

Uma dúvida muito recorrente entre as pessoas é sobre qual a diferença entre Justiça Restaurativa e Mediação, uma vez que ambas funcionam procurando um meio menos formal e com maior participação dos envolvidos para a resolução de conflitos. Há, no entanto, diferença na responsabilidade que se assume nessas formas de se resolver situações conflituosas. Segundo Felizardo (2017) existe na mediação a responsabilidade partilhada e no círculo restaurativo a responsabilidade admitida. Ou seja, na mediação, na maioria das vezes, existem responsabilidades que necessitam ser partilhadas para que o conflito tome novos rumos e chegue, se assim as partes acharem melhor, a ser resolvido sem precisar se recorrer às instâncias judiciais; já na Justiça Restaurativa, através de suas práticas, há necessidade de responsabilização por parte do ofensor (deve reconhecer seu erro e assumi-lo) para que se possa trabalhar a situação e os danos possam ser reparados pelo mesmo. A Justiça Restaurativa se preocupa principalmente em envolver a comunidade que acabou indiretamente envolvida no conflito para que se construa o entendimento que essa situação não deve ocorrer novamente, assim, acarretando relacionamentos melhores no futuro. Outro aspecto muito interessante desta Política Pública é o fato de a mesma ser trabalhada, sempre que possível, por uma equipe interdisciplinar, justamente para que vários enfoques sobre o problema sejam analisados.

Tratando-se de resolver os casos envolvendo o bullying, uma prática bastante válida dentro da Justiça Restaurativa são os círculos restaurativos com ênfase ao círculo de construção de paz, por proporcionar o diálogo entre as partes e onde as emoções têm espaço para serem demonstradas, chegando-se assim, na reconstrução da relação prejudicada. Como já mencionado de forma rápida anteriormente, no modelo de Justiça Restaurativa existe um intermediador/facilitador, que conduz a Prática Restaurativa. Esse facilitador deve ser imparcial e tentar conduzir as partes de forma que o diálogo proporcione a abertura necessária para que as emoções possam ser demonstradas, respeitando a vontade e disponibilidade dos envolvidos. Devido a necessidade de imparcialidade, segundo Felizardo (2017), não é recomendado que o professor dos alunos envolvidos na relação conflituosa trabalhe como facilitador no círculo, pois pode ter predileção por um deles e influenciar na forma como o diálogo se desenvolve e no que é dito no mesmo.

Diversos estados brasileiros já aplicam os círculos restaurativos para solucionar os casos de violência dentro das escolas. Estas práticas estão de acordo com Política Nacional de Resolução de Conflitos no Judiciário, instituída pelo Conselho Nacional de Justiça (CNJ) por meio da Resolução n. 125/2010, e Resolução n. 225/2016, que tem em seu texto diretrizes que autorizam a prática e propagação da Justiça Restaurativa no Poder Judiciário. 0 procedimento do círculo restaurativo dura de três a quatro horas e participam todos os 
envolvidos no conflito; sentados em círculo cada um tem sua oportunidade para falar e ser ouvido (BANDEIRA, 2017).

Segundo Costello; Wachtel; Wachtel (2011), quando um aluno com problemas de comportamento perturba uma sala de aula, os demais são afetados por isso, pois sentem as consequências dessa perturbação. 0 círculo promove para os transgressores a oportunidade de se responsabilizarem pelo comportamento incorreto e proporciona aos colegas a chance de exporem como se sentem. Isso colabora para que o ambiente fique mais leve e amenize os sentimentos de frustrações. 0 procedimento do círculo se divide em três etapas:

0 pré-círculo (preparação para o encontro com os participantes); o círculo, propriamente dito, e o pós-círculo (fase de acompanhamento). 0 trabalho não visa apontar culpados ou vítimas, mas fazer que os presentes entendam que suas ações afetam a si próprios e aos outros e que são responsáveis por seus efeitos (BANDEIRA, 2017).

0 círculo é um símbolo muito forte e sua forma implica inclusão, comunidade, conexão, igualdade, justiça, integridade. Estabelecer um padrão de que os alunos sentem em filas como acontece nas aulas tradicionais limita sua integração. Esse tipo de metodologia não é apropriado para diálogos. Uma reunião em círculo, onde todos estão dispostos da mesma forma, não havendo nem primeiro nem último lugar, proporciona um ambiente de condições iguais para todos os que ali se encontram participando, transformando a relação entre alunos e autoridades. Os alunos participam respondendo o que é questionado porque percebem que o que dizem é importante e sentem-se respeitados (COSTELLO; WACHTEL; WACHTEL, 2011). Os objetivos do círculo, de acordo com Pranis (2010), compreendem: "desenvolver um sistema de apoio àqueles vitimados pelo crime, decidir a sentença a ser cumprida pelos ofensores, ajudá-los a cumprir as obrigações determinadas e fortalecer a comunidade a fim de evitar crimes futuros".

Segundo o Conselho Nacional de Justiça, a Justiça Restaurativa começou a testar suas atividades em ambiente escolar nos Estados de São Paulo, Distrito Federal e Rio Grande do Sul no ano de 2005 . Naquele momento foi criada a figura do professor-mediador que tinha a única função de tomar cuidado para que a boa convivência acontecesse dentro do educandário. Porém, essas ações não se expandiram igualmente pelo resto do país. No ano de 2013, depois de alguns anos suspensa, voltou a ser trabalhada a Justiça Restaurativa dentro das escolas do estado de São Paulo e, desde então, por volta de 50 casos foram solucionados por meio da utilização da técnica do professor-mediador. Nos dias atuais, existem no sistema educacional do estado de São Paulo diversos núcleos de Justiça Restaurativa praticando ações em parceria com as escolas (BANDEIRA, 2017).

No estado do Rio Grande do Sul é também notável a busca por implantar a Justiça Restaurativa como meio de solucionar conflitos nas escolas. Em 2018 foi lançado o programa Escola+Paz que faz parte de outro programa intitulado Programa de Oportunidades e Direitos (POD) e "busca a prevenção e resolução de conflitos, alicerçado no diálogo, nas comunidades escolares dos territórios atendidos pelo POD. Esta iniciativa tem como base a Justiça Restaurativa, que utiliza as práticas dos Círculos de Paz" (ESCOLA+PAZ, 2018).

A ação visando a JR nas escolas é do Governo do Estado do Rio Grande do Sul, por intermédio do Programa de Oportunidades e Direitos (POD) e da Comissão Interna de Prevenção a Acidentes e Violência Escolar (Cipave), em parceria com a Associação dos Juízes do Rio Grande do Sul (Ajuris). De acordo com a página do programa na internet um número significativo de pessoas está se qualificando para atuar com a Justiça Restaurativa, sendo 20 multiplicadores e 1.200 facilitadores. A primeira etapa envolverá comunidades de três municípios gaúchos: Porto Alegre, Alvorada e Viamão. Ao final do programa serão implantados os núcleos e centrais de Práticas Restaurativas nas localidades envolvidas (ESCOLA+PAZ, 2018). 
No município de Caxias do Sul, também no estado do Rio Grande do Sul, a Lei $n^{\circ} 7.754 / 2014$ foi sancionada instituindo o Programa Municipal de Pacificação Restaurativa (CAXIAS DO SUL, 2014), adotando a Justiça Restaurativa como Política Pública Municipal. Percebe-se no texto da lei a preocupação com a violência entre os jovens:

\begin{abstract}
Art.8 ${ }^{\circ}$ : As Centrais de Pacificação Restaurativa são os espaços de serviço destinados ao atendimento da população mediante a aplicação dos métodos de solução autocompositiva de conflitos, bem como à difusão dos princípios e das alternativas metodológicas pacificadoras para aplicações em outros âmbitos de convivência social.

$\S 1^{\circ}$ Ficam criadas as seguintes Centrais de Pacificação Restaurativa:

II- Central de Pacificação Restaurativa da Infância e da Juventude: destinada a atender situações encaminhadas pela rede socioassistencial, envolvendo crianças, adolescentes e seu entorno familiar e comunitário. Visa a oferecer atendimento restaurativo a situações de conflitos, litígios, crimes ou atos infracionais de menor potencial ofensivo, em situações cuja menor relevância jurídica desaconselhe ou torne desnecessária sua judicialização; (CAXIAS DO SUL, 2014)
\end{abstract}

Em seu planejamento estratégico desenvolvido no ano de 2017, a Central de Pacificação Restaurativa da Infância e Juventude estabeleceu como missão promover a Cultura de Paz na rede de proteção à criança e ao adolescente, proporcionando atendimento especializado na resolução de conflitos e no fortalecimento de vínculos. A CPR-IJ quer ser referência nacional em Justiça Restaurativa, pela prática de Círculos de Construção de Paz com crianças e adolescentes, sendo reconhecida por sua competência técnica, pela eficácia das intervenções e como promotora de bem-estar social. A referida Central já realiza um importante trabalho de prevenção e fortalecimento de vínculos nas escolas municipais, sendo o atendimento iniciado com a solicitação da escola à sua mantenedora. Entre os casos de violência está incluído o bullying (FERRONATO; PIZZI, 2018). 0 Programa Caxias da Paz, regulamentado pela lei referida acima, abrange várias centrais, sendo a CPR-IJ uma delas. No ano de 2018, o Programa realizou mais de 19 mil atendimentos à comunidade e dentre as principais ações estão projetos que envolvem escolas (PREFEITURA DE CAXIAS DO SUL, 2019).

Em Londrina, no estado do Paraná, também houve a preocupação de solucionar conflitos no ambiente escolar com responsabilização sem culpabilização, apropriando-se para isso da Justiça Restaurativa, uma vez que foi sancionada em 2016 a Lei $n^{\circ}$ 12.467, que cria o Programa Municipal de Práticas Restaurativas nas Escolas Municipais (LONDRINA, 2016).

\footnotetext{
Art.3: Compete ao Programa Municipal de Práticas Restaurativas os seguintes princípios e objetivos: II - foco na solução autocompositiva e qualificação das relações sociais, dentro e fora das salas de aula, no tratamento de conflitos e problemas concretos;

III - abordagem metodológica dialogal, empática, não persecutória, responsabilizante sem culpabilização, capaz de assegurar espaços seguros e protegidos que permitam o enfrentamento de questões difíceis; IV - participação direta dos envolvidos, mediante a articulação e das micro-redes de pertencimento familiar e comunitário em conjunto com as redes profissionalizadas; (LONDRINA, 2016).
}

Nota-se, com esses exemplos, que a prática da JR vem se propagando pelos estados e municípios do Brasil e que a preocupação por resolver os conflitos escolares com responsabilização sem culpabilização, com diálogo e reparação dos danos, é uma realidade. O bullying, se caracterizando muitas vezes como um conflito violento entre os jovens, também acaba por ser abrangido por essas legislações que criam programas pensando em solucionar situações conflituosas com a ajuda da Justiça Restaurativa.

Portanto, é notável que a Justiça Restaurativa está tomando espaço dentro do Poder Judiciário também como modo de resolver os conflitos escolares principalmente pelo fato de proporcionar a recuperação das relações prejudicadas e por não visar punir o agressor, mas fazê-lo entender que seu comportamento é errado e 
deve ser repensado para que ele e a comunidade na qual está inserido sejam beneficiados com sua mudança de atitude.

\section{CONSIDERAÇÕES FINAIS}

Diante da proporção que tomou o bullying entre os jovens, principalmente no ambiente escolar, é notória a relevância da promulgação da Lei $n^{\circ} 13.185 / 2015$ na prevenção e combate as condutas que sejam intimidadoras, visto que, estabelece o que de fato é o bullying e como dever ser tratado, também designando que é importante a capacitação dos docentes e que se deve utilizar de meios alternativos para tratar a violência. Com o surgimento da referida Lei, questionou-se se havia possibilidade de aplicar as Práticas Restaurativas como meio de solucionar o bullying dentro das escolas e de acordo com a pesquisa realizada para elaboração deste artigo, contatou-se que é sim possível aplicar-se as Práticas Restaurativas no ambiente escolar, que esse procedimento já está sendo adotado em algumas escolas no Brasil e tem demonstrado resultados positivos, como ficou evidenciado com os dados apresentados a respeito das iniciativas de aplicação da Justiça Restaurativa em cidades da Região Sudeste e Sul do país. No estado do Rio Grande do Sul, mais de mil pessoas estão sendo capacitadas para atuar como facilitadores nas práticas restaurativas que serão executadas inicialmente em escolas da região metropolitana; em Caxias do Sul, no mesmo estado, através do programa intitulado Caxias da Paz, mais de 19 mil atendimentos utilizando práticas restaurativas foram realizados em 2018, sendo muitos deles envolvendo o ambiente escolar. Em São Paulo, as informações divulgadas pelo CNJ atestam que mais de 50 casos já foram resolvidos com auxílio da Justiça Restaurativa. Na cidade de Londrina, estado do Paraná, uma lei municipal que passou a vigorar em 2016 estabelece a criação de um projeto de Práticas Restaurativas nas escolas municipais.

Foram também abordados aspectos das transformações do conceito de bullying na atual era da globalização, chegando-se ao conceito de cyberbullying, que é o bullying praticado no ambiente virtual com o auxílio das novas tecnologias e que causa prejuízos psicológicos tão graves quanto o cometido de forma presencial, visto que o anonimato do ofensor torna a situação ainda mais dolorosa para a vítima que não sabe o motivo e de onde partem as agressões. As perspectivas jurídicas e sociais estudadas neste artigo mostraram que a Lei $n^{\circ} 13.185 / 2015$ tem se mostrado de certa forma eficaz, uma vez que, propiciou a capacitação de docentes para tratar o bullying e a implementação de meios alternativos para tratar o conflito, se sobressaindo desse modo, a Justiça Restaurativa através de suas Práticas Restaurativas, para trabalhar o conflito de forma mais humana, criativa e sensível, reconstruindo relações prejudicadas e responsabilizando os agressores sem culpá-los, mas sim, os fazendo compreender que seu comportamento é errado e causa dor, angústia e tantos outros problemas para a vida de quem foi ou é vítima de bullying. Assim é possível que as agressões cessem, que a relação entre todos os envolvidos seja restaurada e fortalecida com valores como o respeito, a compreensão e a empatia, resultando em um ambiente aprazível para a convivência de todos.

Para que se possa compreender a violência escolar, é preciso considerar a realidade onde a mesma está inserida, o seu contexto e suas reais condições de fazer com que o aluno se sinta integrado a sua escola. A violência na escola pode representar a ausência de um sentimento de identidade e de pertencimento do aluno, que muitas vezes, por sentir-se excluído da comunidade escolar, não participa da formulação de regras e, por isso mesmo, não entende o contrato social ali firmado, não se sentindo, desta forma, com o compromisso de respeitá-lo. A escola é o espaço onde o aluno deve ser convidado a trabalhar em equipe, a construir valores e 
ideias na busca de um objetivo comum. As Práticas Restaurativas podem auxiliar a escola na construção deste espaço de cooperação entre os atores escolares, visando a construção de regras que beneficiem a todos. $A$ escola que não propicia aos seus alunos um ambiente social baseado na afetividade, no amor e respeito ao outro, está produzindo violência. E quando este ambiente é percebido como hostil e ameaçador, os alunos podem repetir esta prática. A Justiça Restaurativa desenvolverá ainda, o poder da escuta, da reflexão e autocrítica, fundamentais para o desenvolvimento da moral do ser humano.

\section{REFERÊNCIAS}

ANTUNES, Deborah Christina. Bullying: razão instrumental e preconceito. São Paulo: Casa do Psicólogo, 2010.

BANDEIRA, REGINA. Mediação de conflitos nas escolas em busca da pacificação social. Agência CNJ de notícias, 2017. Disponível em: http://www.cnj.jus.br/noticias/cnj/85116-mediacao-de-conflitos-nas-escolas-em-busca-dapacificacao-social. Acesso em: 05 mai.2018.

BRASIL. Lei n. 13.185, de 6 de novembro de 2015. Institui o Programa de Combate à Intimidação Sistemática (Bullying). Diário Oficial [da] República Federativa do Brasil, Brasília, DF, 6 nov. 2015. Disponível em: http://www.planalto.gov.br/ccivil_03/_ato2015-2018/2015/lei/l13185.htm. Acesso em: 16 abr. 2018.

BRASIL. Lei $\mathrm{n}^{\circ}$ 13. 277, de 29 abril de 2016 . Institui o dia 7 de abril como o Dia Nacional de Combate ao Bullying e à Violência na Escola. Diário Oficial [da] República Federativa do Brasil, Brasília, DF, 29 de abril de 2016. Disponível em: http://www.planalto.gov.br/ccivil_03/_ato2015-2018/2016/lei/L13277.htm. Acesso em: 10 nov. 2018.

CAXIAS DO SUL. Lei $n^{\circ}$ 7754, de 29 de abril de 2014. Institui o Programa Municipal de Pacificação Restaurativa, e dá outras providências. Leis Municipais. Caxias do Sul, 29 de abril de 2014. Disponível em: https://leismunicipais.com.br/a/rs/c/caxias-do-sul/lei-ordinaria/2014/775/7754/lei-ordinaria-n-7754-2014institui-o-programa-municipal-de-pacificacao-restaurativa-e-da-outras-providencias. Acesso em: 13 nov. 2018.

COSTA, M,M.M; DIEHL, R. C. O Redirecionamento da Esfera Pública pela Coparticipação da Sociedade Civil portes sobre a Promoção do Acesso à Justiça nas Comunidades da América do Sul. In: COSTA, M,M.M; DIEHL, R. C; PORTO, R.T.C (orgs). Direito na Atualidade. Curitiba: Multideia, 2017.

COSTELLO, Bob; WACHTEL, Joshua; WACHTEL, Ted. Círculos Restaurativos nas escolas: construindo um sentido de comunidade e melhorando o aprendizado. International Institute for Restorative Practices. Bethlehem: CECOSAMI, 2011.

DIEHL, R.C; PORTO, R.T.C. A cultura simbólica e punitiva do direito penal no Brasil: os avanços sociais e os desafios da Política Nacional de Justiça Restaurativa a partir da resolução $n^{\circ} .225 \mathrm{CNJ} / 2016$. UEPG. Ponta Grossa, 2016 . Disponível em: http://www.revistas2.uepg.br/index. php/sociais. Acesso em: 27 abr. 2018.

ESCOLA+PAZ. O Programa. Escola+Paz. 2018?. Disponível: www.escolamaispaz.org.br/oprograma. Acesso em: 20 dez.2018.

FELIZARDO, Aloma Ribeiro. Bullying escolar: prevenção, intervenção e resolução com princípios da justiça restaurativa. Curitiba: InterSaberes, 2017.

FARIELLO, Luiza de Carvalho. Brasil tem papel crucial no avanço da Justiça Restaurativa, diz especialista. Agência CNJ de Notícias, 2015. Disponível em: http://www.cnj.jus.br. Acesso em: 15 abr. 2018.

FERRONATO, A.; PIZZI, R. A Justiça Restaurativa na infância e juventude. In: DAMIANI, S.; HANSEL, C.M.; QUADROS, M.S.P. de (orgs). Justiça restaurativa na prática : ações realizadas no município de Caxias do Sul. Caxias do Sul, RS: Educs, 2018. Disponível em: https://www.ucs.br/site/midia/arquivos/ebook-justicarestaurativa.pdf. Acesso em: 20 jun. 2019.

JAHNKE, L.T; GAGLIETTI, M. O avanço tecnológico e os conflitos 
comportamentais nas redes sociais - o Cyberbullying. In: CONGRESSO INTERNACIONAL DE DIREITO E CONTEMPORANEIDADE, 2012 ,Santa Maria. Anais... Universidade Federal de Santa Maria: 2012. Disponível em: http://coral.ufsm.br/congressodireito/anais/2012/35.pdf. Acesso em: 17 abr. 2018.

LONDRINA. Lei n 12.467, de 6 de dezembro de 2016. Cria o Programa Municipal de Práticas Restaurativas nas Escolas Municipais e dá outras providências. Leis Municipais. Londrina, 6 de dezembro de 2016. Disponível em:https://leismunicipais.com.br/a/pr/I/londrina/lei-ordinaria/2016/1246/12467/lei-ordinaria-n-124672016-cria-o-programa-municipal-de-praticas-restaurativas-nas-escolas-municipais-e-da-outras-providencias. Acesso em: 12 nov.2018.

MINAYO, Maria Cecília Souza. O desafio do conhecimento: pesquisa qualitativa em saúde. São Paulo: Hucitec; Rio de Janeiro: Abrasco, 2000.

MINISTÉRIO DA EDUCAÇÃO. MEC apoia enfrentamento ao bullying e violência nas escolas.Ministério da Educação, 2018.Disponível em: http://portal.mec.gov.br/ultimas-noticias/222-537011943/62581-mec-apoiaenfrentamento-ao-bullying-e-violencia-nas-escolas. Acesso em: 22 dez.2018.

PEREIRA, G.R.; RODRIGUES, T.D. 0 bullying no âmbito escolar: algumas reflexões. Interfaces da Educação, Paranaíba, v.3, n. 9, 2012. Disponível em:

http://periodicosonline.uems.br/index.php/interfaces/article/view/554/518. Acesso em: 08 nov. 2018.

PORTo, R.T.C.; CAVALhEIRO, R. A. A. Aprendendo o Direito e Prevenindo o Bullying nas Escolas no Município de Sobradinho - RS. In: COSTA, M,M.M; DIEHL, R. C; PORTO, R.T.C (orgs). Direito na Atualidade. Curitiba: Multideia, 2017.

PORTO, Rosane Terezinha Carvalho. A Justiça Restaurativa e as Políticas Públicas de Atendimento a Criança e ao Adolescente no Brasil: uma análise a partir da experiência da $3^{a}$ vara do juizado regional da infância e da juventude de Porto Alegre, Santa Cruz do Sul: 2008. Disponível em: http://www.dominiopublico.gov.br/download/teste/arqs/cp060751.pdf. Acesso em: 15 abr.2018.

PRANIS, Kay. Processos Circulares/ Kay Pranis; tradução de Tônia Van Acker. São Paulo: Palas Athena, 2010.

PREFEITURA DE CAXIAS DO SUL. Programa Caxias da Paz atende mais de 19 mil pessoas em 2018. 2019. Disponível em: https:// caxias.rs.gov.br/noticias/2019/01/programa-caxias-da-paz-atende-mais-de-19-milpessoas-em-2018. Acesso em: 10 jun. 2019.

SILVA, Ana Beatriz Barbosa. Bullying: mentes perigosas nas escolas. Rio de Janeiro: Objetiva, 2010.

ZEHR, Howard. Trocando as lentes: um novo foco sobre o crime e a justiça. Tradução de Tônia Van Acker. São Paulo: Palas Athena, 2008. 